\title{
Antiretroviral therapy, pregnancy, and birth defects: a discussion on the updated data
}

This article was published in the following Dove Press journal:

HIVIAIDS - Research and Palliative Care

31 July 2013

Number of times this article has been viewed

\author{
Luiz Euribel Prestes- \\ Carneiro ${ }^{1-2}$ \\ 'Immunology Department, University \\ of Oeste Paulista, Presidente \\ Prudente, São Paulo, Brazil; ${ }^{2}$ Infectious \\ Diseases Department, Hospital \\ Ipiranga, São Paulo, SP, Brazil
}

\begin{abstract}
An increasing number of HIV-infected women of childbearing age are initiating antiretroviral therapy (ART) worldwide. This review aims to discuss updated data of the eligible ART regimens and their role in inducing birth defects in utero. Zidovudine and lamivudine plus a non-nucleoside reverse-transcriptase inhibitor or protease inhibitor (PI) is the first-line regimen applied. The role of zidovudine exposition monotherapy or associated with other ART in inducing birth defects remains inconclusive. The main organ systems involved are genitourinary and cardiovascular. For HIV-infected pregnant women, World Health Organization (WHO) guidelines up to 2010 recommend the same group of drugs that are prescribed to nonpregnant women. The exception is efavirenz, which has been associated with an increase in the risk of teratogenicity. Increased rates of birth defects were found in large cohorts and computational studies conducted recently in infants exposed to efavirenz-containing regimens. The combination of zidovudine and lamivudine and lopinavir/ritonavir is one of the most used ART regimens for prevention of mother-to-child-transmission. Conflicting data about the role of PI exposure in utero and birth defects have been reported. However, a reduced number of studies evaluating the role of PI in inducing birth defects in women are available. An association between prematurity and PI exposure in pregnancy was extensively described. Some questions arise due to the tendency of initiating ART early in the life of HIV-infected individuals or those at risk of infection. Longtime exposure to different ART regimens and the potential effect of birth-defect induction in pregnancy are not completely understood. Developing regions harbor the highest numbers of women of reproductive age exposed to ART. Most of the largest and expressive data come from developed countries, and could not be sufficiently representative of pregnant women living in developing countries.
\end{abstract}

Keywords: antiretroviral therapy, pregnancy, birth defects

\section{Background}

Globally, 34.0 million people were living with HIV at the end of 2011, and most of the new infections were transmitted heterosexually. Mode of HIV transmission is sexual for most people who are newly infected. Women represent about half of all people living with HIV, the main cause of death among women of reproductive age. Particularly in developing countries, women make up a vulnerable population, being at risk at a reproductive age. ${ }^{1}$ At the end of 2011, there were 3.3 million children living with HIV around the world and 330,000 new infections among children, most of them living in sub-Saharan Africa. This dramatic scenario is mainly a result of mother-tochild transmission (MTCT). ${ }^{1}$ In the absence of any intervention, the risk of MTCT is $15 \%-45 \%$, with a risk of $15 \%-30 \%$ during pregnancy and delivery and an additional 
risk of $10 \%-20 \%$ postpartum via breastfeeding. ${ }^{2}$ The risk can be reduced to less than $2 \%$ through the combination of preventive interventions. One of the most important measures is antiretroviral therapy (ART). Treatment of mothers living with HIV benefits not only the mothers themselves but also their children. ${ }^{1,2}$

In 1994, the landmark Pediatric AIDS Clinical Trials Group study 076 (PACTG076), promoted a rapid implementation and a significant reduction in perinatal HIV transmission in the US and other developed countries. Zidovudine monotherapy given orally to pregnant women and to newborns promoted a reduction of $70 \%$ in MTCT. ${ }^{3}$ Since then, a significant reduction has been noted in developed and developing countries. In 1998, the US Public Health Service recommended the use of combined ART for treating pregnant women and preventing MTCT of HIV. ${ }^{4}$ This review aims to discuss updated data of the eligible ART regimens and their role in inducing birth defects in utero.

\section{Methods}

\section{Study selection}

This review summarizes studies identified by systematic literature searches of both Medline and PubMed. The following combinations of search terms were used: "antiretroviral therapy and pregnancy" and "birth defects". Additionally, hand searches of the reference lists of all included articles identified during the search period were performed to locate any additional relevant studies. Requirements for inclusion criteria were descriptive studies written in English, published from January 1995 through March 2013, with sample sizes higher than 100
HIV-infected, ART-treated, pregnant women. According to predefined inclusion criteria, articles that appeared to be potentially relevant were identified by the reviewer after reviewing titles and abstracts.

\section{Results \\ Systematic review}

On the basis of a review of the abstracts of the articles, 107 studies were initially identified as being potentially eligible for inclusion. After abstract and full-text analysis, 66 fulfilled the inclusion criteria and 41 were discarded.

\section{Treatment and prophylaxis of MTCT}

In 2006 the World Health Organization (WHO) guidelines recommended regimens involving three different drugs - zidovudine, lamivudine, and nevirapine - resulting in increased rates of MCTC reduction than monotherapy., In 2010, the WHO revised MTCT guidelines and defined two strategies: (1) long-term first-line ART regimens for HIV-infected women in need of treatment for their own health, which is also safe and effective in reducing MTCT of HIV, and lifelong treatment should start as soon as possible during pregnancy (Table 1); and (2) short-term ART prophylaxis to reduce MTCT during pregnancy, delivery, and breastfeeding for HIV-infected women not in need of treatment. For short-term ART, the 2010 guidelines include two options, both of which should start earlier in pregnancy: at 14 weeks or as soon as possible (Table 2)., Worldwide, zidovudine/lamivudine with a non-nucleoside reverse-transcriptase inhibitor (NNRTI) or a protease inhibitor (PI) is the eligible combination regimen in ARTnaive pregnant women. However, for women who are

Table I Antiretroviral treatment options recommended for HIV-infected pregnant women who are eligible for treatment

Maternal ART + infant ARV prophylaxis
Mother
Meternal antepartum daily ART, starting as soon as possible irrespective of gestational age, and continued
during pregnancy, delivery and thereafter. Recommended regimens include:
AZT + 3TC + NVP or
AZT + 3TC + EFV* or
TDF + 3TC (or FTC) + NVP or
TDF + 3TC (or FTC) + EFV*
Infant

Daily NVP or twice-daily AZT from birth until 4 to 6 weeks of age (irrespective of the mode of infant feeding).

Note: *Avoid use of EFV in the first trimester and use NVP instead. For all exposed infants, regardless of infant feeding, reprinted with permission World Health Organization (Antiretroviral drugs for treating pregnant women and preventing HIV infection in infants, 2010 version. Available from: http://whqlibdoc.who.int/publications/20I0/978924I5998I8 eng.pdf. Accessed March 20, 2013). ${ }^{7}$

Abbreviations: ART, antiretroviral therapy; ARV, antiretroviral; AZT, zidovudine; NVP, nevirapine; TDF, tenofovir; EFV, efavirenz; 3TC, lamivudine; FTC, emtricitabine; XTC, 3TC lamivudine. 
Table 2 ARV-prophylaxis options recommended for HIV-infected pregnant women who do not need treatment for their own health

\begin{tabular}{|c|c|}
\hline $\begin{array}{l}\text { Maternal AZT + infant ARV prophylaxis } \\
\text { (Option A) }\end{array}$ & $\begin{array}{l}\text { Maternal triple ARV prophylaxis } \\
\text { (Option B) }\end{array}$ \\
\hline Mother & Mother \\
\hline $\begin{array}{l}\text { Antepartum twice-daily AZT starting from as early as } \\
14 \text { weeks of gestation and continued during } \\
\text { pregnancy. At onset of labour, sd-NVP and initiation of } \\
\text { twice daily AZT + 3TC for } 7 \text { days postpartum. } \\
\text { (Note: If maternal AZT was provided for more than } 4 \\
\text { weeks antenatally, omission of the sd-NVP and } \\
\text { AZT + 3TC tail can be considered; in this case, } \\
\text { continue maternal AZT during labour and stop at } \\
\text { delivery). }\end{array}$ & $\begin{array}{l}\text { Triple ARV prophylaxis starting from as early as } 14 \\
\text { weeks of gestation and continued until delivery, or, if } \\
\text { breastfeeding, continued until } 1 \text { week after all infant } \\
\text { exposure to breast milk has ended. Reecommended } \\
\text { regimens include: } \\
\text { AZT + 3TC + LPV/r or } \\
\text { AZT + 3TC + ABC or } \\
\text { AZT + 3TC + EFV or } \\
\text { TDF + 3TC (or FTC) + EFV }\end{array}$ \\
\hline Infant & Infant \\
\hline $\begin{array}{l}\text { For breastfeeding infants } \\
\text { Daily NVP from birth for a minimum of } 4 \text { to } 6 \text { weeks, } \\
\text { and until } 1 \text { week after all exposure to breast milk has } \\
\text { ended. } \\
\text { Infants receiving replacement feeding only } \\
\text { Daily NVP or sd-NVP + twice-daily AZT from birth until } \\
4 \text { to } 6 \text { weeks of age. }\end{array}$ & $\begin{array}{l}\text { Irrespective of mode of infant feeding } \\
\text { Daily NVP or twice-daily AZT from birth until } 4 \text { to } 6 \\
\text { weeks of age. }\end{array}$ \\
\hline
\end{tabular}

Notes: Single-dose NVP and AZT + 3TC can be omitted if mother receives $>4$ weeks' AZT antepartum. Begin as early as I4 weeks' gestation (second trimester) or as soon as possible thereafter. Reprinted with permission World Health Organization (Antiretroviral drugs for treating pregnant women and preventing HIV infection in infants, 2010 version. Available from: http://whqlibdoc.who.int/publications/2010/978924I5998I8 eng.pdf. Accessed March 20, 2013). ${ }^{7}$

Abbreviations: ARV, antiretroviral; AZT, zidovudine; ART, antiretroviral therapy; NVP, nevirapine; LPV, lopinavir; ABC, abacavir; EFV, efavirenz; 3TC, lamivudine; FTC, emtricitabine; SD, single dose; TDF, tenofovir.

intolerant to zidovudine due to severe anemia or who have developed resistance to the drug, alternative regimens can be used. For ART-naive pregnant women with CD4 cell lymphocyte counts $<250$ cells $/ \mathrm{mm}^{3}$, nevirapine would be the preferred NNRTI. However, the drug should not be given to naive women with CD4 cell counts $>250$ cells $/ \mathrm{mm}^{3}$ due to the risk of nevirapine toxicity. An increased risk of symptomatic and possible fatal rash and hepatic toxicity should be considered. ${ }^{8}$ According to the Recommendations for Use of Antiretroviral Drugs in Pregnant HIV-1-Infected Women for Maternal Health and Interventions to Reduce Perinatal HIV Transmission in the United States, the main alterations induced in animal models or humans by ART are clastogenic (causing disruption or breakages in chromosomes), mutagenic (inducing or capable of inducing genetic mutation), genotoxic (damaging to genetic material such as DNA and chromosomes), or carcinogenic (producing or tending to produce cancer). Some agents, such as certain chemicals or forms of radiation, are both mutagenic and clastogenic. Teratogenic (any agent or factor that induces or increases the incidence of abnormal prenatal development). ${ }^{8}$
The use of ART is one of the main steps for HIV-infected pregnant women, both for their own treatment and for MTCT. The main ART regimens used worldwide are grouped into four categories: nucleoside analog reverse-transcriptase inhibitor (NRTI) only; NRTI and NNRTI; combination of NRTI and PI; or a combination of NRTI, NNRTI, and PI. Highly active antiretroviral therapy (HAART) is defined as regimens including three or more drugs. ${ }^{8}$ For initiating an ART regimen in a pregnant HIV-infected woman, the choice should be individualized and must be based on discussion about the available data from the individual drugs. The history and evolution of the infection should be taken into account, as should whether the treatment is indicated for own health or only for MTCT, the presence of comorbidities, and access and drug availability. Moreover, some HIV-infected women have never received ART previously or may not be receiving ART at the time they are pregnant. With an increasing number of pregnant HIV-infected women receiving ART worldwide, concerns have been raised over the possible side effects linked to exposure in early pregnancy, mainly in the first trimester. This trimester is the period of greatest susceptibility to teratogens, since it is when germ-layer 
formation and organogenesis occur, defined as up to and including 12 gestational weeks. ${ }^{8-10}$

Congenital abnormalities were classified according to WHO criteria as any major structural or chromosomal abnormality, or any cluster of two or more minor (conditional) abnormalities, occurring in fetuses of at least 20 weeks of gestational age (polydactyly, malformed ear, abnormalities in the feet, minor mouth abnormalities, undescended testes, accessory nipple, spinal hairy patch, strawberry nevi, skin tag, and subclinical subependymal cysts). Similar criteria are used by the $\mathrm{APR}^{11}$ and by the Metropolitan Atlanta Congenital Defects Project. ${ }^{12}$

\section{In utero ART exposure and birth defects}

Data on the potential teratogenic effect of ART drugs include animal toxicity data, anecdotal experience, cohort studies, case reports, and data from such agencies as the PACTG, ${ }^{13}$ European Collaborative Study, ${ }^{14}$ Pediatric European Network for Treatment of AIDS, ${ }^{15}$ National Institute of Child Health and Human Development International Site Development Initiative (NISDI), ${ }^{16}$ and the APR, the largest agency that registers ART regimens and pregnancy outcomes worldwide. Created in 1989, the APR collects data on birth defects after ART exposure in pregnancy. It estimates the risk of birth defects against different classes of ART, including case-report retrospective and prospective studies. The data are compared with rates from a population-based surveillance system, and first-trimester exposure is compared with second-/third-trimester exposure. ${ }^{11}$ Preclinical data include both in vitro and in vivo results of animal screening tests for carcinogenicity, clastogenicity/mutagenicity, and reproductive and teratogenic effects. Data on the risk of birth defects after ART exposure are limited and conflicting, with some studies showing risk similar to a populationbased surveillance and others finding increased risks after specific exposure.

\section{Nucleoside analog reverse-transcriptase inhibitors and birth defects}

Since the hallmark study of PACTG076, ${ }^{3}$ zidovudine has become routine for most HIV-infected pregnant women for preventing MTCT. However, rising concerns of congenital

Table 3 Results of major studies associated with birth defects on zidovudine monotherapy and zidovudine-containing regimen exposure in utero

\begin{tabular}{|c|c|c|c|c|c|}
\hline Study & $\begin{array}{l}\text { Antiretroviral } \\
\text { therapy }\end{array}$ & $\begin{array}{l}\text { Number } \\
\text { enrolled }\end{array}$ & $\begin{array}{l}\text { Number } \\
\text { exposed }\end{array}$ & $(\%) *$ & Rates compared to controls \\
\hline Sperling et $\mathrm{al}^{4}$ & ZDV & 437 & 437 & 0.7 & $\begin{array}{l}\text { Lower than APR and US pediatric } \\
\text { population }\end{array}$ \\
\hline Mandelbrot et $\mathrm{al}^{21}$ & $\begin{array}{l}Z D V \\
Z D V+3 T C\end{array}$ & 1344 & 1344 & 3 & Similar to newborns in Paris (2.7\%) \\
\hline Patel et a ${ }^{22}$ & $\begin{array}{l}\text { ZDV } \\
\text { ZDV + 3TC + HAART }\end{array}$ & 3740 & 1973 & 1.6 & $\begin{array}{l}\text { Similar compared to controls not } \\
\text { exposed (I.4\%) }\end{array}$ \\
\hline Watts et $\mathrm{a}^{23}$ & $\begin{array}{l}\text { ZDV } \\
\text { ZDV + NRTI } \\
\text { ZDV + NRTI + NNRTI }\end{array}$ & 2527 & 2527 & 3.5 & Similar to US pediatric population ( $2.7 \%)$ \\
\hline Townsend et $\mathrm{a}^{24}$ & $\begin{array}{l}Z D V \\
Z D V+3 T C \\
Z D V+N R T I+N N R T I\end{array}$ & 8242 & 8242 & 2.8 & Similar to Europe newborns (2.2\%) \\
\hline Gibb et $a^{30}$ & $\begin{array}{l}\text { ZDV } \\
\text { ZDV + NRTI }\end{array}$ & 1867 & 226 & 3 & Similar to international data (1.4\%-3.9\%) \\
\hline Nielsen-Saines et $\mathrm{al}^{29}$ & $\begin{array}{l}\text { ZDV } \\
Z D V+N R T I+N N R T I\end{array}$ & 236 & 236 & 7.6 & High compared to international data \\
\hline Newschaffer et al ${ }^{10}$ & ZDV & 1932 & 1917 & 10.5 & $\begin{array}{l}2.79 \text { times higher than New York } \\
\text { newborns }\end{array}$ \\
\hline Joao et $\mathrm{a}^{25}$ & ZDV & 974 & 954 & 6.0 & $\begin{array}{l}\text { High compared to newborns of Rio de } \\
\text { Janeiro, Brazil (2.2\%) }\end{array}$ \\
\hline Brogly et $\mathrm{a}^{26}$ & ZDV & 2202 & 33 & 5.5 & High compared to APR (2.9\%) \\
\hline Watts et $\mathrm{al}^{27}$ & $\begin{array}{l}Z D V \\
Z D V+N R T I \\
Z D V+N R T I+P I\end{array}$ & 1414 & 1113 & 3.5 & High compared to CDC (2.2\%) \\
\hline Knapp et $\mathrm{a}^{28}$ & ZDV & 1112 & 944 & 5.5 & High compared to APR (2.9\%) \\
\hline
\end{tabular}

Note: *Prevalence per 100 live births.

Abbreviations: ZDV, zidovudine; NRTI, nucleoside analog reverse-transcriptase inhibitor; NNRTI, non- nucleoside analog reverse-transcriptase inhibitor; 3TC, lamivudine; PI, protease inhibitor; HAART: highly active antiretroviral therapy, APR, antiretroviral pregnancy register; US, United States; CDC, Centers of Disease Control and Prevention. 
malformations, including potential cancers, mitochondrial disease, and heart, hematological, and genitourinary abnormalities, appeared from animal models and clinical trials performed in developing and developed countries due to zidovudine exposure. ${ }^{17-20}$ Zidovudine plus lamivudine is a recommended dual-NRTI regimen for pregnant women. ${ }^{21}$ Zidovudine is classified by the FDA as category $\mathrm{C}$, indicating that the drug may have teratogenic effects; however, the available information is insufficient. ${ }^{7,8}$ One of the first scientific studies on the role of ART in congenital abnormalities, particularly to zidovudine, was the perinatal cohort trial PACTG $076 .{ }^{4}$ The main results of major studies exploring the role of zidovudine monotherapy or zidovudinecontaining regimens in inducing birth defects in utero are summarized in Table 3.4,10,21-30 The sequence follows the time course over which the studies were published. Among the eleven selected studies, six showed similar rates of birth defects in zidovudine monotherapy or zidovudinecontaining regimens compared to the Centers for Disease Control and Prevention, APR, or the European pediatric population. In addition, the risk was not significantly higher for mothers in the first trimester compared with second-/thirdtrimester exposure. Furthermore, the presence of congenital abnormalities was not associated with the use of monotherapy (zidovudine), dual therapy (zidovudine/lamivudine), or HAART regimens. Two of them were conducted in the US, ${ }^{4,10,21-30}$ three in Europe, ${ }^{21,22,24}$ and one in Africa. ${ }^{30}$ In the US Women and Infants Transmission Study, ${ }^{23}$ an association between first-trimester exposure to zidovudine and a tenfoldincreased risk of hypospadias among male newborns was described, although birth-defect rates were not different from the general US pediatric population. The same observation was reported by Townsend et al, ${ }^{24}$ including twelve cases of hypospadias in infants exposed to zidovudine-containing regimens.

Conflicting results are described, showing higher levels of birth defects in infants exposed to zidovudine alone or in combined regimens. Five major studies showing increased rates of birth defects associated with zidovudine or zidovudinecontaining regimens in utero were selected. According to a study by Joao et $\mathrm{al}^{25}$ carried out in Brazil and Argentina, one possibility of the higher prevalence of birth defects found in this study than rates from the US and Europe could be attributed to the prospective model of the study. In addition, small cohorts destined to determine the prevalence of birth defects were designed in Latin America, and rates ranged from $0.4 \%$ in Vitoria (Brazil) to $8.4 \%$ in Chile. ${ }^{25}$ In PACTG 219 and 219C, zidovudine exposure exerted a higher risk of heart defects, increasing with advancing maternal age, although these findings were based on a small number of cases. An association of zidovudine and septal heart defect was previously reported in litarature. ${ }^{26,27}$ Among the 80 organsystem anomalies identified in the International Maternal Pediatric Adolescent AIDS Clinical Trials Group (IMPAACT) protocol P1025, cardiovascular $(\mathrm{n}=33)$, musculoskeletal $(n=15)$, renal $(n=9)$, genitourinary $(n=6)$, craniofacial $(n=4)$, and central nervous system $(n=2)$ were included. ${ }^{28}$ In a multisite study conducted in infants exposed to ART from Africa, India, Thailand, and Brazil, 18/236 (7.6\%) showed congenital defects/inborn errors of metabolism, of which 17 were from Thailand. ${ }^{29}$ Summarizing, in zidovudine monotherapy or zidovudine-containing regimens, the main organ systems involved are genitourinary and cardiovascular. In the selected studies, no increase in birth defects was found between first and second/third trimester of in utero exposure to zidovudine/lamivudine or PIs. The role of zidovudine alone or associated with other ART exposure in utero in inducing birth defects in HIV-infected pregnant women or in women at childbearing age remains sparse.

\section{Non-nucleoside reverse-transcriptase inhibitors and birth defects}

Millions of HIV-infected women in developed and developing countries are in need of safe and effective ART. ${ }^{30}$ Except for efavirenz, which has been associated with a potential increase in the risk of teratogenicity in women of childbearing age,

Table 4 Results of major studies associated with birth defects on efavirenz-containing regimen exposure in utero

\begin{tabular}{|c|c|c|c|c|}
\hline Study & $\begin{array}{l}\text { Number } \\
\text { enrolled }\end{array}$ & $\begin{array}{l}\text { Number } \\
\text { antenatal } \\
\text { exposure }\end{array}$ & $(\%)^{*}$ & $\begin{array}{l}\text { Rates compared } \\
\text { to controls or } \\
\text { international data }\end{array}$ \\
\hline Bera et $\mathrm{al}^{37}$ & 623 & 623 & 2.6 & $\begin{array}{l}\text { Similar to } \\
\text { international data } \\
(1.4 \%-3.9 \%)\end{array}$ \\
\hline $\begin{array}{l}\text { Townsend } \\
\text { et } \mathrm{a}^{24}\end{array}$ & 8242 & 205 & 2.4 & $\begin{array}{l}\text { Similar to Europe } \\
\text { newborns }(2.2 \%)\end{array}$ \\
\hline Ford et $\mathrm{al}^{32}$ & 8295 & 1132 & 3.0 & $\begin{array}{l}\text { Similar to APR } \\
(2.9 \%)\end{array}$ \\
\hline $\begin{array}{l}\text { Antiretroviral } \\
\text { Pregnancy }\end{array}$ & 679 & 679 & 2.7 & $\begin{array}{l}\text { Similar to US } \\
\text { newborns }(2.0 \%)\end{array}$ \\
\hline \multicolumn{5}{|l|}{ Register"I } \\
\hline Ekouevi et al ${ }^{36}$ & 344 & 213 & 0 & Lower than APR \\
\hline Brogly et $\mathrm{a}^{26}$ & 105 & 5 & 15.6 & $\begin{array}{l}\text { Higher than APR } \\
\text { and CDC data }\end{array}$ \\
\hline Knapp et $\mathrm{al}^{38}$ & 1112 & 56 & 10.7 & $\begin{array}{l}\text { Higher than APR } \\
\text { and CDC data }\end{array}$ \\
\hline
\end{tabular}

Note: *Prevalence per 100 live births.

Abbreviations: APR, Antiretroviral Pregnancy Register; CDC, Centers for Disease Control and Prevention. 
guidelines up to 2010 recommend the same group of drugs that are prescribed to nonpregnant HIV-infected mothers. In 2005 , the drug was classified by the US FDA as a class $\mathrm{C}$ drug (drugs in which risk cannot be ruled out). This recommendation is based on animal studies with cynomolgus monkeys, in which significant malformations (anencephaly, anophthalmia, and cleft palate), were observed in three out of 20 infants (15\%) receiving efavirenz during the first trimester. The plasma levels of the drug are comparable to systemic human therapeutic exposure. ${ }^{7,8}$ The first trimester of pregnancy is the critical time for neural tube formation. Subsequently, due to retrospective and prospective case reports of neural tube defects in humans with first-trimester exposure to efavirenz, the FDA reclassified the drug as class D (there is positive evidence of human fetal risk based on studies in humans, but potential benefits may warrant use of the drug in pregnant women despite potential risks). ${ }^{8,31-35}$ Although the FDA recommends other ARTs than efavirenz for childbearing women or HIV-infected pregnant women in the first trimester, in 2010, WHO guidelines recommend the use of efavirenz as first line for developed and developing countries: zidovudine/lamivudine/efavirenz or tenofovir/lamivudine (or emtricitabine)/efavirenz. ${ }^{7}$ The role of efavirenz-containing regimens in inducing birth defects in HIV-pregnant women remains inconclusive. Seven major studies were selected, ${ }^{11,24,26,32,36-38}$ and the results are summarized in Table 4.

Classified by organs, in the study of Townsend et al, ${ }^{24}$ undescended testes, hip dislocation, and hypertrophic and pyloric stenosis were the most prevalent. In the multisite US cohort PATCTG protocols 219 and 219C, the defects included laryngomalacia, meningomyelocele with Arnold-Chiari malformation type II, hypospadias, varus feet, hypertonicity of extremities, and cleft palate. ${ }^{26}$ Bussmann et al described in pregnant women on efavirenz-containing regimens in Botswana, polydactyly, umbilical hernia, shortening of the right lower extremity, and one live birth showing shortened right femur with midshaft cortical thickening, absence of right femur head epiphysis, and dysplastic right fibular head. ${ }^{38}$ In a computer simulation model, investigators from the Cost-Effectiveness of Preventing AIDS Complications (CEPAC) used literature-based rates of live births and teratogenic reports of HIV-infected women to calculate the risk of teratogenic events. Simulations were conducted for women both receiving efavirenz and non-efavirenz-based regimens. For women without efavirenz exposure during pregnancy, the rate of teratogenic events was 72.46 events per 100,000 women. For women exposed to efavirenz during pregnancy, the rate was 77.26 events per 100,000 women. They concluded that efavirenz exposure was associated with a small (4.8 per 100,000 women) increased risk of teratogenic events. ${ }^{39}$ Another HIV computer simulation model was also applied in Côte d'Ivoire to analyze the results of either efavirenz or nevirapine as an ART regimen in women of childbearing age in a cohort of 100,000 women. Similarly, it was concluded that initiating ART with efavirenz instead of nevirapine induces a smaller potential number of birth defects compared to women with no efavirenz-containing regimens. ${ }^{40}$ In most of these studies, the prevalence of birth defects was not significantly different between the first and second/third trimester of efavirenz exposure or even compared with exposure to other ART. However, according to the APR, although some data provide sufficient numbers of first-trimester exposures to rule out a twofold or greater increase in the risk of overall birth defects, the low incidence of neural tube defects in the general population means that a larger number of exposures are still needed to make it possible to rule out definitively an increased risk of this specific defect. ${ }^{11}$

\section{Protease inhibitors}

Several national guidelines recommend the combination of antiretroviral regimens for prevention of MTCT of HIV and for the treatment of maternal HIV infection. In HIV-infected pregnant women, the combination of zidovudine, lamivudine, and a PI is one of the most used regimens for both preventing MTCT and treatment of HIV infection itself. In the US, ten PIs are available based on several clinical trials in human pregnancy. ${ }^{8}$ There are a lot of data available for lopinavir/ ritonavir, atazanavir, nelfinavir, ritonavir, and saquinavir. Not many data are available for darunavir, fosamprenavir, and indinavir. Very limited data are available for tipranavir. ${ }^{8,41,42}$ Although experience is more limited with these regimens, depending on the side effects, resistance to ART, and other limiting circumstances, alternative PIs include ritonavirboosted atazanavir or saquinavir regimens. Nelfinavir and indinavir can be considered for prophylaxis of perinatal transmission in ART-naive women who cannot tolerate alternative agents. However, indinavir has been associated with renal stones developing. Darunavir can also be used, but there are few studies showing the role of the drug exposition in in utero and birth defects. Fosamprenavir and tipranavir can also be considered for women who are intolerant to other agents. ${ }^{8,41,42}$ Overwhelmingly, the combination of zidovudine + lamivudine and lopinavir/ritonavir is one of the most widely used worldwide ART regimens for prevention 
of MTCT of HIV, especially in ART-naive pregnant women. ${ }^{1,2,5,11}$

Conflicting data are reported about the role of PI exposition in in utero and birth defects. However, a reduced number of studies of pregnant women in use of PI are available. In the European Collaborative study, 3740 mother-infant pairs were enrolled, and 1973 infants were exposed to ART in utero, 789 received HAART in the first trimester of pregnancy, and no increase in birth defects were found between children exposed to lopinavir/ ritonavir and nonexposed infants. ${ }^{9}$ The NISDI group found in the first extensive prospective study of birth defects in Latin America a prevalence of $4.3 \%$ of birth defects in 94 children exposed to two NRTIs + one PI. ${ }^{25}$ In studies in Ireland and the UK between 1990 and 2006, the use of PIs in HAART regimens increased from 36.1\% in 1999 to $73.2 \%$ in 2006 , and birth defects were not higher in infants exposed to PIs than in nonexposed ones. Of note, there are higher prematurity rates found in children exposed to PIs than those on monotherapy or dual therapy. ${ }^{24}$ The association between prematurity and PI exposition in pregnancy has been extensively described previously. Recently, Watts et al through the Pediatric HIV/AIDS Cohort Study network's Surveillance Monitoring for ART Toxicities showed that use of PIs early in pregnancy may be associated with increased risk of prematurity. ${ }^{43}$ In the PACTP 219 and 219C cohorts, the rate of birth defects was higher in children exposed to lopinavir/ritonavir in the first trimester than in unexposed children, including hydronephrosis, supernumerary nipple, umbilical hernia, atrial septal defect, pyloric stenosis, ventricular septal defect, and hemangioma. ${ }^{26}$

\section{Where are we going now?}

The tendency of initiating ART earlier in HIV-infected individuals or for preexposure prophylaxis raises some questions. (1) The use of prophylaxis of ART in serodiscordant couples and in individuals at risk of HIV infection, such as prostitutes and injecting drug users or HIV-infected individuals with CD4 count 350-500 cells/ $\mathrm{mL}$, increases the period of ART exposure in women of childbearing age. ${ }^{44,45}$ Moreover, in developed and especially in developing countries, a significant number of young women are exposed and more susceptible to HIV infection, increasing the ART exposition as well. ${ }^{1,46}$ The role of longterm exposure to different ART regimens and the potential effect of birth-defect induction in pregnancy are not well known. Overwhelmingly, in these regions, young women are exposed to multiple risk factors, such as undernutrition, anemia, increasing number of pregnancies and conceptions early in life, unsure treatment access, and irregular use of ART. ${ }^{47}$ The role of such interactions in induction of birth defects is not completely understood. (2) Developing regions such as sub-Saharan Africa and Latin American countries harbor the highest numbers of women of reproductive age exposed to ART. ${ }^{1,25,47,48}$ Most of the largest and expressive data comes from retrospective, prospective, and case-report studies carried out in developed countries and could be not sufficiently representative of pregnant women living in developing countries. Both extensive cohorts and expressive studies in these populations are missing. ${ }^{47,48}$ In some of these regions, higher rates of birth defects were found in small cohorts. ${ }^{25}$ (3) ART drugs not commonly used in standard protocols are being used with increasing frequency in HIVinfected pregnant women or of childbearing age, mainly in developing countries. At the moment, few studies are available to determine the role of these drugs alone or associated with other ART in inducing birth defects. ${ }^{49}$ Answers to these questions should be urgently addressed by researchers.

Among the limitations of our updated review is that only English-language articles were included. Furthermore, few studies conducted in poor-resource settings with limited applicability due to the small number of enrolled participants were selected.

\section{Disclosure}

The author reports no conflict of interest in this work.

\section{References}

1. Joint United Nations Programme on HIV/AIDS (UNAIDS). Global Report: UNAIDS Report on the Global AIDS Epidemic - 2012. Geneva: UNAIDS; 2012. Available from: http://www.unaids.org/ en/media/unaids/contentassets/documents/epidemiology/2012/ gr2012/20121120_UNAIDS_Global_Report_2012_en.pdf. Accessed May 27, 2013.

2. Wettstein C, Mugglin C, Egger M, et al. Southern Africa Collaboration. Missed opportunities to prevent mother-to-child-transmission: systematic review and meta-analysis. AIDS. 2012;26(18):2361-2373.

3. Connor EM, Sperling RS, Gelber R, et al. Reduction of maternal-infant transmission of human immunodeficiency virus type 1 with zidovudine treatment. Pediatric AIDS Clinical Trials Group Protocol 076 Study Group. N Engl J Med. 1994;331(18):1173-1180.

4. Sperling RS, Shapiro DE, McSherry GD, et al. Safety of the maternalinfant zidovudine regimen utilized in the Pediatric AIDS Clinical Trial Group 076 Study. AIDS. 1998;12(14):1805-1813.

5. World Health Organization: Antiretroviral therapy for HIV infection in adults and adolescents. Recommendations for a public health approach (2006 revision). Available from: whttp://www.who.int/hiv/pub/arv/adult/ en/. Accessed March 20, 2013.

6. Orne-Gliemann J, Becquet R, Ekouevi DK, Leroy V, Perez F, Dabis F. Children and HIV/AIDS: from research to policy and action in resourcelimited settings. AIDS. 2008;22(7):797-805. 
7. World Health Organization HIV/AIDS Program. Antiretroviral drugs for treating pregnant women and preventing HIV infection in infants, 2010 version. Available from: http://whqlibdoc.who.int/publications/2010/9789241599818_eng.pdf. Accessed March 20, 2013.

8. Panel on Treatment of HIV-Infected Pregnant Women and Prevention of Perinatal Transmission. Recommendations for Use of Antiretroviral Drugs in Pregnant HIV-1-Infected Women for Maternal Health and Interventions to Reduce Perinatal HIV Transmission in the United States. Washington: DHHS; 2012. Available from: http://aidsinfo.nih.gov/ contentfiles/lvguidelines/perinatalgl.pdf. Accessed May 27, 2013.

9. Mirochnick M, Best BM, Clarke DF. Antiretroviral pharmacology: special issues regarding pregnant women and neonates. Clin Perinatol. 2010; 37(4):907-927.

10. Newschaffer CJ, Cocroft J, Anderson CE, Hauck WW, Turner BJ. Prenatal zidovudine use and congenital anomalies in a Medicaid population. J Acquir Immune Defic Syndr. 2000;24(3):249-256.

11. The Antiretroviral Pregnancy Register. 2012. Available from: http://www.apregistry.com/forms/interim_report.pdf. Accessed March 15, 2013.

12. Correa-Villaseñor A, Cragan J, Kucik J, O’Leary L, Siffel C, Williams L. The Metropolitan Atlanta Congenital Defects Program: 35 years of birth defects surveillance at the Centers for Disease Control and Prevention. Birth Defects Res A Clin Mol Teratol. 2003;67(9): $617-624$.

13. Nachman SA, Chernoff M, Gona P, et al. Incidence of noninfectious conditions in perinatally HIV-infected children and adolescents in the HAART era. Arch Pediatr Adolesc Med. 2009;163(2):164-171.

14. European Collaborative Study. The mother-to-child HIV transmission epidemic in Europe: evolving in the East and established in the West. AIDS. 2006;20(10):1419-1427.

15. Sharland M, di Zub GC, Ramos JT, Blanche S, Gibb DM. PENTA guidelines for the use of antiretroviral therapy in pediatric HIV infection. Pediatric European Network for Treatment of AIDS. HIV Med. 2002;3(3):215-226.

16. Read JS, Duarte G, Hance LF, et al. The NICHD International Site Development Initiative perinatal cohorts (2002-2009). Int J Epidemiol. 2012;41(3):642-649.

17. Witt KL, Cunningham CK, Patterson KB, et al. Elevated frequencies of micronucleated erythrocytes in infants exposed to zidovudine in utero and postpartum to prevent mother-to-child transmission of HIV. Environ Mol Mutagen. 2007;48(3-4):322-329.

18. Watts DH, Huang S, Culnane M, et al. Birth defects among a cohort of infants born to HIV-infected women on antiretroviral medication. J Perinat Med. 2011;39(2):163-170.

19. Borojerdi JP, Ming J, Cooch C, et al. Centrosomal amplification and aneuploidy induced by the antiretroviral drug AZT in hamster and human cells. Mutat Res. 2009;665(1-2):67-74.

20. Thorne C, Newell ML. Safety of agents used to prevent mother-tochild transmission of HIV: is there any cause for concern? Drug Saf. 2007;30(3):203-213.

21. Mandelbrot L, Landreau-Mascaro A, Rekacewicz C, et al. Lamivudinezidovudine combination for prevention of maternal-infant transmission of HIV-1. JAMA. 2001;285(16):2083-2093.

22. Patel D, Thorne C, Fiore S, Newell ML. Does highly active antiretroviral therapy increase the risk of congenital abnormalities in HIV-infected women? J Acquir Immune Defic Syndr. 2005;40(1):116-118.

23. Watts DH, Li D, Handelsman E, et al. Assessment of birth defects according to maternal therapy among infants in the Women and Infants Transmission Study. J Acquir Immune Defic Syndr. 2007;44(3): 299-305.

24. Townsend CL, Cortina-Borja M, Peckham CS, Tookey PA. Trends in management and outcome of pregnancies in HIV-infected women in the UK and Ireland, 1990-2006. BJOG. 2008;115(9): $1078-1086$
25. Joao EC, Calvet GA, Krauss MR, et al. Maternal antiretroviral use during pregnancy and infant congenital anomalies: the NISDI perinatal study. J Acquir Immune Defic Syndr. 2010;53(2):176-185.

26. Brogly SB, Abzug MJ, Watts DH, et al. Birth defects among children born to human immunodeficiency virus-infected women: pediatric AIDS clinical trials protocols 219 and 219C. Pediatr Infect Dis J. 2010;29(8):721-727.

27. Watts DH, Huang S, Culnane M, et al. Birth defects among a cohort of infants born to HIV-infected women on antiretroviral medication. $J$ Perinat Med. 2011;39(2):163-170.

28. Knapp KM, Brogly SB, Muenz DG, et al. Prevalence of congenital anomalies in infants with in utero exposure to antiretrovirals. Pediatr Infect Dis J. 2012;31(2):164-170.

29. Nielsen-Saines K, Komarow L, Cu-Uvin S, et al. Infant outcomes after maternal antiretroviral exposure in resource-limited settings. 2012;129(6):e1525-e1532.

30. Gibb DM, Kizito H, Russell EC, et al. Pregnancy and infant outcomes among HIV-infected women taking long-term ART with and without tenofovir in the DART trial. PLoS Med. 2012;9(5):e1001217.

31. Jeantils V, Khuong MA, Delassus JL, et al. Efavirenz (Sustiva) in pregnancy: a study about $12 \mathrm{HIV}$ patients. Gynecol Obstet Fertil. 2006;34(7-8):593-596. French.

32. Ford N, Calmy A, Mofenson L. Safety of efavirenz in the first trimester of pregnancy: an updated systematic review and meta-analysis. AIDS. 2011;25(18):2301-2304.

33. De Santis M, Carducci B, De Santis L, Cavaliere AF, Straface G. Periconceptional exposure to efavirenz and neural tube defects. Arch Intern Med. 2002;162(3):355.

34. Saitoh A, Hull AD, Franklin P, Spector SA. Myelomeningocele in an infant with intrauterine exposure to efavirenz. J Perinatol. 2005;25(8): $555-556$.

35. Shanske AL. Bilateral oblique facial clefts and extremity anomaly in an infant after intrauterine efavirenz exposure and review of its teratogenic risk. AIDS. 2012;26(14):1775-1779.

36. Ekouevi DK, Coffie PA, Ouattara E, et al. Pregnancy outcomes in women exposed to efavirenz and nevirapine: an appraisal of the IeDEA West Africa and ANRS Databases, Abidjan, Côte d'Ivoire. J Acquir Immune Defic Syndr. 2011;56(2):183-187.

37. Bera E, McCausland K, Nonkwelo R, Mgudlwa B, Chacko S, Majeke B. Birth defects following exposure to efavirenz-based antiretroviral therapy during pregnancy: a study at a regional South African hospital. AIDS. 2010;24(2):283-289.

38. Bussmann $\mathrm{H}$, Wester $\mathrm{CW}$, et al. Pregnancy rates and birth outcomes among women on efavirenz-containing highly active antiretroviral therapy in Botswana. J Acquir Immune Defic Syndr. 2007;45(3): 269-273.

39. Hsu HE, Rydzak CE, Cotich KL, et al. Quantifying the risks and benefits of efavirenz use in HIV-infected women of childbearing age in the U S A. HIV Med. 2011;12(2):97-108.

40. Ouattara EN, Anglaret X, Wong AY, et al. Projecting the clinical benefits and risks of using efavirenz-containing antiretroviral therapy regimens in women of childbearing age. AIDS. 2012;26(5):625-634.

41. Sturt AS, Dokubo EK, Sint TT. Antiretroviral therapy (ART) for treating HIV infection in ART-eligible pregnant women. Cochrane Database Syst Rev. 2010;17;(3):CD008440.

42. Heidari S, Mofenson L, Cotton MF, Marlink R, Cahn P, Katabira E. Antiretroviral drugs for preventing mother-to-child transmission of HIV: a review of potential effects on HIV-exposed but uninfected children. J Acquir Immune Defic Syndr. 2011;57(4):290-296.

43. Watts DH, Williams PL, Kacanek D, et al. Combination antiretroviral use and preterm birth. $J$ Infect Dis. 2013;207(4):612-621.

44. Baeten JM, Donnell D, Ndase P, et al. Antiretroviral prophylaxis for HIV prevention in heterosexual men and women. $N$ Engl J Med. 2012;367(5):399-410. 
45. Van Damme L, Corneli A, Ahmed K, et al. Preexposure prophylaxis for HIV infection among African women. N Engl J Med. 2012;367(5): 411-422.

46. Hernández CM. HIV/AIDS in childbearing Hispanic/Latinas: an emerging crisis. MCN Am J Matern Child Nurs. 2011;36(6):354-358.

47. Santhya KG. Early marriage and sexual and reproductive health vulnerabilities of young women: a synthesis of recent evidence from developing countries. Curr Opin Obstet Gynecol. 2011;23(5): 334-339.
48. Shetty AK. Epidemiology of HIV infection in women and children: a global perspective. Curr HIV Res. 2013;11(2):81-92.

49. Hartman TL, Buckheit RW Jr. The continuing evolution of HIV-1 therapy: identification and development of novel antiretroviral agents targeting viral and cellular targets. Mol Biol Int. 2012;2012:401965.

\section{Publish your work in this journal}

HIV/AIDS - Research and Palliative Care is an international, peerreviewed open-access journal focusing on advances in research in HIV, its clinical progression and management options including antivira treatment, palliative care and public healthcare policies to contro viral spread. The journal welcomes original research, basic science, clinical \& epidemiological studies, reviews \& evaluations, expert opinion \& commentary, case reports \& extended reports. The manuscript management system is completely online and includes a very quick and fair peer-review system. Visit http://www.dovepress.com/ testimonials.php to read real quotes from published authors.

Submit your manuscript here: http://www.dovepress.com/hivaids---research-and-palliative-care-journal 